\title{
Inherited renal tubular dysgenesis with novel homozygous mutation in angiotensin-1-converting enzyme gene: A case report
}

\author{
Michal Kalman*1, Tatiana Burjanivova² ${ }^{2}$ Gabriel Minarik ${ }^{3}$, Veronika Janusicova Holubekova ${ }^{2}$, Lukas Plank ${ }^{1}$ \\ ${ }^{1}$ Department of Pathology, Comenius University in Bratislava, Jessenius Faculty of Medicine and University Hospital in Martin, \\ Martin, Slovak Republic \\ ${ }^{2}$ Department of Molecular Biology, Comenius University in Bratislava, Jessenius Faculty of Medicine in Martin, Martin, Slovak \\ Republic \\ ${ }^{3}$ Institute of Molecular Biology, Comenius University in Bratislava, Faculty of Natural Sciences, Bratislava, Slovak Republic
}

Received: October 29, 2015

Accepted: November 22, $2015 \quad$ Online Published: December 11, 2015

DOI: $10.5430 /$ crcp.v3n1p39

URL: http://dx.doi.org/10.5430/crcp.v3n1p39

\begin{abstract}
Renal tubular dysgenesis (RTD) is a serious developmental disorder of kidneys, characterized by typical clinical-pathological features, which include an early onset of anuria with oligohydramnios, the Potter sequence and refractory hypotension resulting from poorly differentiated proximal tubules. The prognosis is poor and most of the affected fetuses die in utero or in neonatal period. The disease may be acquired or inherited. Here we report a case of a newborn with RTD who was transferred to our intensive care unit (ICU) after preterm delivery of young healthy primipara. The newborn died after 11 hours despite the appropriate intensive care. Genetic analyses indicated after evaluation of renal histology confirmed the diagnosis of RTD. A novel homozygous R259C mutation in the gene coding angiotensin-1-converting enzyme (ACE) was found. Consequent mutation analysis found the same heterozygous mutations in both parents, who are asymptomatic. The identification of causal mutation is an important finding; allowing not only estimation of theoretical risk of recurrence, but also allowing future parents and their family members to benefit from genetic testing and early prenatal diagnosis.
\end{abstract}

Key Words: Renin-angiotensin system, Renal tubular dysgenesis, Angiotensin-converting enzyme, Histomorphology, Gene mutation

\section{INTRODUCTION}

Renal tubular dysgenesis (RTD) is a rare serious developmental kidney disorder either acquired or inherited with typical clinical-pathologic features and poor prognosis. The nongenetic RTD are caused by fetus exposure to some drugs, twin-to-twin transfusion syndrome, severe congenital cardiac malformations, renal artery stenosis, etc. ${ }^{[1]}$ Inherited RTD is well known longer time, but the causal mutations in the genes encoding renin-angiotensin system associated with RTD were first reported in 2005. ${ }^{[2]}$ They affect angiotensin II production or function and represent a defect responsible for abnormal kidney development. ${ }^{[3]}$ However, the clinical phenotype of RTD seems to be remarkably similar regardless of the mutation type, although some of them might be respon-

\footnotetext{
*Correspondence: Michal Kalman; Email: kalman@unm.sk; Address: Department of Pathology, Comenius University in Bratislava, Jessenius Faculty of Medicine and University Hospital in Martin, Slovak Republic.
} 
sible for milder autosomal recessive nephropathies. ${ }^{[4]} \mathrm{We}$ present a genetically determined RTD primary recognized at autopsy analysis of the affected neonate after typical prenatal clinical presentation. In our case, the novel RTD causative mutation in angiotensin-1-converting enzyme (ACE) gene
(R259C) was discovered, confirming the genetic basis of the disease in this family. The diagnosis was based on histomorphological analyses and confirmed by genetic testing with serious consequences for the next pregnancy.
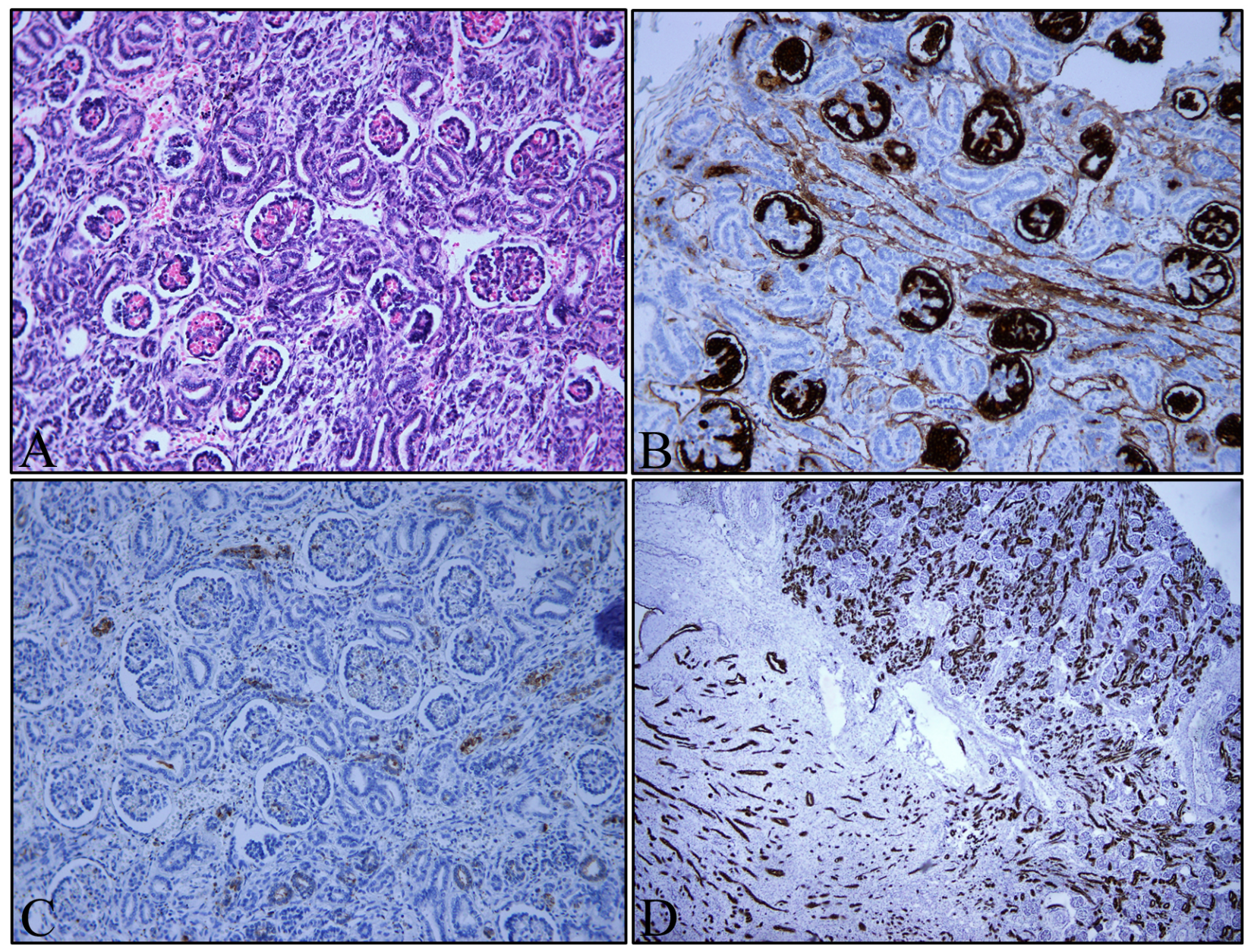

Figure 1. Histomorphology and immunohistochemistry (A) H\&E stained sections of the kidneys showed crowding of mildly enlarged glomeruli in renal cortex and absence of normal-appearing proximal convoluted tubules. Hypoplastic tubules in the nephrogenic zone were lined by small darkly stained epithelial. There were also scattered Henle loops with collapsed collecting ducts surrounded by increased amounts of interstitial mesenchyme (not shown on image). Negative immunohistochemical detection of (B) CD10 and (C) CD15 normally expressed in epithelial of proximal tubules. In contrast, strong labelling of all tubules (cortical and medullar) was seen with (D) anti-EMA antibody, normally a marker of distal tubules and collecting ducts.

\section{CASE PRESEnTAtion}

The mother was a healthy 21-year-old primipara with no previous significant medical history. A prenatal ultrasound scan in 16th gestational week revealed normal amniotic fluid volume. Next controls allowed detection of oligohydramnios in 25 th week progressing to anhydramnion in week 35 , in presence of two normal-sized kidneys and empty urinary bladder. The neonate was delivered before term by an emergency caesarean section. At delivery, a male neonate with weight of 2,300 $\mathrm{g}$ and length of $45 \mathrm{~cm}$ was cyanotic with bradycardia, apnoe, hypotonia and complicated postnatal adaptation. The neonate was immediately transferred to our university hospital intensive care unit with severe respiratory acidosis and anuria requiring ventilation with blood circulation support. In spite of intensive treatment the neonate died eleven hours after the delivery. Cytogenetic analysis revealed 46XY karyotype. At autopsy, the infant had the Potter phenotype with wide cranial sutures and fontanels. The 
lungs were hypoplastic. Anatomically configured kidneys were moderately enlarged, with normal corticomedullary demarcation and calyx structures, the ureters were of normal calibre. Neither genitourinary nor other abnormalities were observed. Histomorphological and immunohistochemical analysis of the kidneys was performed (see Figure 1).

Genetic analysis was based on DNA isolated from fixed and paraffin-embedded autopsy specimens (kidneys, heart, liver). Direct sequencing revealed a novel homozygous mutation of ACE in exon 5, in which codon CGC coding for Arginin at position 259 is substituted in both alleles by codon TGC for Cystein. R259C mutation was present in all samples and was evaluated with the prediction tool PolyPhen-2 as probably damaging with a score of 1,000 . Consequent mutation analyses found identical mutation in heterozygous form in both asymptomatic parents.

\section{Discussion}

RTD is a serious developmental kidney disorder with typical a clinical-pathological features and poor prognosis. Prenatal period is characterized by an early onset of oligohydramnios after 18 weeks of gestation in the absence of ruptured membranes leading to the Potter sequence with skull ossification defects (i.e., wide sutures and fontanels) with renal ultrasound showing kidneys of normal size and shape with hyperechogenicity and poor corticomedullary differentiation of various degrees. Fetuses with RTD die in utero or, more often, are born preterm with severe course including anuria, respiratory distress due to secondary lung hypoplasia, and refractory hypotension. As in the present case, most of them die during the early postnatal period. Only nine children with longer survival were reported; however, eight of them developed chronic end-stage renal disease and only one having normal renal function with kidney hyperechogenicity. ${ }^{[3,5]}$ The choice of treatment should be an early administration of mineralocorticoids in addition to inotropic agents and peritoneal dialysis in order to overcome extreme hypotension and hyperkalemia observed in surviving cases. ${ }^{[5]}$ Uematsu et al. reported that also infusions of fresh frozen plasma (FFP) in the early neonatal period may help to promote long survival when a diagnosis of angiotensinogen deficiency is confirmed antenatally. ${ }^{[6]}$

For diagnosis of both acquired and inherited RTD, histopathologic examination of the macroscopically normal or nearly normal-appearing kidneys is necessary. The main identifying feature is the poorly differentiated proximal convoluted tubules lined by flat or cuboidal cells without brush border. ${ }^{[7]}$ Abnormal tubules are negative for CD10 and CD15 antigens, normally expressed by proximal tubules. On the other hand, they show strong apical immunelabeling for epithelial membrane antigen (EMA) a marker of distal tubules and collecting ducts. ${ }^{[8]}$ Typical is immunohistochemical proof of marked renin expression of the juxtaglomerular apparatus cells. ${ }^{[8]}$ However, this antibody is not included in standard equipment in most laboratories. Other nonspecific histomorphological features include crowding of glomeruli, atrophic Henle loops in the medulla, collapsed collecting ducts, overgrowth of the interstitial mesenchyme and thickening and disorganization of the arteriolar muscular wall. ${ }^{[7,8]}$

This severe congenital disorder can be acquired during fetal development or inherited as an autosomal recessive disease with the high incidence of parental consanguinity. The most commonly acquired form of RTD is that observed in fetuses exposed to drugs, especially ACE inhibitors and angiotensin II receptor antagonists. ${ }^{[9,10]}$ Vulnerable fetuses are exposed to drugs during the second and/or third trimester of pregnancy. Neonates are anuric and hypotensive. Even after progressive recovery of diuresis, longterm follow-up of patients is necessary because of the high risk of persistent or secondary renal insufficiency. ${ }^{[10]}$ Several cases are linked to the use of NSAIDs during pregnancy and one case is also associated with maternal cocaine abuse. ${ }^{[11-13]}$ Other nongenetic cause of RTD is twin-to-twin transfusion syndrome, when vascular anastomoses in the monochorionic placenta cause circulatory imbalance leading to chronic hypoperfusion of the donor twin. ${ }^{[14]}$ Severe congenital cardiac malformations and renal artery stenosis are other etiologic factors of non-inherited forms of RTD. There is evidence that severe, long-standing artery stenosis, even in adults, may cause tubular atrophy. RTD was also reported in neonates with neonatal hemochromatosis. The liver is the main producer of angiotensinogen, which is the precursor of angiotensin. Insufficient production of this protein due to liver injury likely results in low perfusion pressure, which is important for kidney development. ${ }^{[15]}$ Inherited RTD is autosomal recessive disease of the renin-angiotensin system. Mutations in four well-known RAS genes encoding renin (REN), ACE, angiotensinogen (AGT) and type 1 angiotensin II receptor (AGTR1) have been found. These mutations, which were first identified by Gribouval et al. affect the production or function of angiotensin II (ANGII), a defect responsible for abnormal kidney development resulting in severe refractory hypotension observed at birth. ${ }^{[3]}$ In inherited RTD the ACE mutations are the most frequent ones, observed in two-thirds of families, and most of these mutations are new. ${ }^{[16]}$ The frequency of subsequent mutations that affect the genes in question is in the following order: REN, AGT and AGTR1 genes. No correlation was observed between the mutated gene and the phenotype. However, one reported RTD patient suffered no respiratory distress at birth and showed sponta- 
neous recovery of diuresis. ${ }^{[16]}$ This patient had a missense mutation in the ACE gene affecting the C-terminal part of the extracellular domain. ${ }^{[16]}$ This case suggests that some mutations in RAS could be responsible for milder autosomal recessive nephropathies. Similarly, recently identified heterozygous REN mutations affecting the signal sequence of the protein are also associated with autosomal dominant chronic tubulointerstitial nephropathy, hyperuricaemia and early anaemia. ${ }^{[17]}$ Diagnosis of RTD is important for its severe clinical course and for its possibility for recurrence in case of the inherited form. Its identification based on a precise clinical and histopathological analyses allows genetic counseling and early prenatal diagnosis. In our case, the RTD diagnosis and consequent genetic counseling revealed parental consanguinity. Consequent mutation analyses found identical heterozygous mutations in both asymptomatic parents. Two years later mother spontaneously conceived and

\section{REFERENCES}

[1] Quan A. Fetopathy associated with exposure to angiotensin converting enzyme inhibitors and angiotensin receptor antagonists. Early Hum Dev. 2006; 82(1): 23-8. http://dx.doi.org/10.1016/j.e arlhumdev. 2005.11.001

[2] Gribouval O, Gonzales M, Neuhaus T, et al. Mutations in genes in the renin-angiotensin system are associated with autosomal recessive renal tubular dysgenesis. Nat Genet. 2005; 37(9): 964-8. http://dx.doi .org/10.1038/ng1623

[3] Gubler MC, Antignac C. Renin-angiotensin system in kidney development: renal tubular dysgenesis. Kidney Int. 2010; 77: 400-6. http://dx.doi.org/10.1038/ki.2009.423

[4] Gubler MC. Renal tubular dysgenesis. Pediatr.Nephrol. 2014; 29: 51-59. http://dx.doi .org/10.1007/s00467-013-2480-1

[5] Schreiber R, Gubler MC, Gribouval O, et al. Inherited renal tubular dysgenesis may not be universally fatal. Pediatr. Nephrol. 2010; 25: 2531-4. http://dx.doi.org/10.1007/s00467-010-1584-0

[6] Uematsu M, Sakamoto O, Nishio T, et al. A case surviving for over a year of renal tubular dysgenesis with compound heterozygous angiotensinogen gene mutations. Am J Med Genet A. 2006 Nov 1; 140(21): 2355-60. http://dx.doi.org/10.1002/ajmg.a.3144 8

[7] Voland JR, Hawkins EP, Wells TR, et al. Congenital hypernephronic nephromegaly with tubular dysgenesis: a distinctive inherited renal anomaly. Pediatr Pathol. 1985; 4: 231-45. PMid: 3835549. http://dx.doi.org/10.3109/15513818509026897

[8] Lacoste M, Cai Y, Guicharnaud L, et al. Renal tubular dysgenesis, a not uncommon autosomal recessive disorder leading to oligohydramnios: role of the reninangiotensin system. J Am Soc Nephrol. 2006; 17: 2253-63. PMid: 16790508. http://dx.doi.org/10.1681/A SN. 2005121303

[9] Martinovic J, Benachi A, Laurent N, et al. Fetal toxic effects of angiotensin II receptor antagonists. Report of three additional cases. at 17th week of gestation amniocentesis was performed. Genetic screening of amniotic fluid identified homozygous R259C mutation of ACE gene of the fetus. After the counseling with multidisciplinary team about the prognosis and treatment options, the parents decided to have an abortion.

\section{ACKNOWLEDGEMENTS}

This work was supported by Center of Excellence for Perinatologic Research II (co-financed from ITMS code 26220120036), IOCGRD (ITMS code 26110230067) and by "Increasing Opportunities for Career Growth in Research and Development in the Field of Medical Sciences", ITMS: 26110230067, co-funded from EU sources and European Social Fund (T.B., V.H.), as well as by education grant from Pfizer code 26220220113. We would like to thank Dr. Marie Claire Gubler and Dr. Vincent Morinie, Paris, France for providing us primer sequences and IHC staining for $\mathrm{ACE}$ and renin.
Lancet. 2001; 358: 241-2. http://dx.doi.org/10.1016/S0140 -6736 (01) 05426-5

[10] Spaggiari E, Heidet L, Grange G, et al. Prognosis and outcome of pregnancies exposed to renin-angiotensin system blockers. Prenat Diagn. 2012; 32: 1-6. http://dx.doi.org/10.1002/pd. 3960

[11] Ali US, Khubchandani S, Andankar P, et al. Renal tubular dysgenesis associated with in utero exposure to Nimuselide. Pediatr Nephrol. 2006 Feb; 21(2): 274-6. PMid: 16328538. http: //dx.doi.org/10.1007/s00467-005-2089-0

[12] Butler-O'Hara M, D'Angio CT. Risk of persistent renal insufficiency in premature infants following the prenatal use of indomethacin for suppression of preterm labor. J Perinatol. 2002; 22(7): 541-6. http://dx.doi.org/10.1038/sj.jp.7210790

[13] Schwartz BR, LageJM, Pober BR, et al. Isolated congenital renal tubular immaturity in siblings. Hum Pathol. 1986; 17(12): 1259-63. http://dx.doi.org/10.1016/S0046-8177 (86)80570-6

[14] Oberg KC, Pestaner JP, Bielamowicz L, et al. Renal tubular dysgenesis in twin-twin transfusion syndrome. Pediatr Dev Pathol. 1999; 2(1): 25-32. PMid: 9841703 . http://dx.doi .org/10.1007/s10 0249900086

[15] Bonilla SF, Melin-AldanaH, Whitington PF. Relationship of Proximal Renal Tubular Dysgenesis and Fetal Liver Injury in Neonatal Hemochromatosis. Pediatr Res. 2010; 67(2): 188-93. http: //dx.doi.org/10.1203/PDR.0b013e3181c2df69

[16] Gribouval O, Morinière V, Pawtowski A, et al. Spectrum of mutations in the renin-angiotensin system genes in autosomal recessive renal tubular dysgenesis. Hum Mutat. 2012; 33(2): 316-26. http://dx.doi.org/10.1002/humu.21661

[17] Zivná $\mathrm{M}$, Hůlková $\mathrm{H}$, Matignon $\mathrm{M}$, et al. Dominant renin gene mutations associated with early-onset hyperuricemia, anemia, and chronic renal failure. Am J Hum Genet. 2009; 85: 204-213. http: //dx.doi.org/10.1016/j.ajhg.2009.07.010 